Please do not remove this page

RMIT

UNIVERSITY

\title{
A room temperature polyaniline nanofibre hydrogen gas sensor
}

Sadek, Abu; Trinchi, Adrian; Wlodarski, Wojtek; Kalantar-Zadeh, Kourosh; Galatsis, Kosmas; Baker, Christina; Kaner, R.B.

https://researchrepository.rmit.edu.au/esploro/outputs/9921859443001341/filesAndLinks?institution=61RMIT_INST\&index=null

Sadek, A., Trinchi, A., Wlodarski, W., Kalantar-Zadeh, K., Galatsis, K., Baker, C., \& Kaner, R. B. (2005). A room temperature polyaniline nanofibre hydrogen gas sensor. Proceedings of the Fourth IEEE Sensors 2005 Conference, 207-210. https://doi.org/10.1109/ICSENS.2005.1597672

Published Version: https://doi.org/10.1109/ICSENS.2005.1597672

Repository homepage: https://researchrepository.rmit.edu.au

(c) 2005 IEEE. Personal use of this material is permitted. However, permission to reprint/republish this material for advertising or promotional purposes or for creating new collective works for resale or redistribution to servers or lists, or to reuse any copyrighted component of this work in other works must be obtained from the IEEE.

Downloaded On 2023/04/26 21:33:06 +1000 


\section{A Room Temperature Polyaniline Nanofiber Hydrogen Gas Sensor}

\author{
A. Z. Sadek, A. Trinchi, W. Wlodarski, \\ K. Kalantar-zadeh \\ Sensor Technology Laboratory, School of Electrical \\ \& Computer Engineering, RMIT University, \\ Melbourne, Australia \\ Email: wojtek.wlodarski@rmit.edu.au
}

\author{
K. Galatsis ${ }^{1}$, C. Baker ${ }^{2}$ and R.B. Kaner ${ }^{2}$ \\ ${ }^{1}$ Device Research Lab., Dept. of Electrical Engineering, \\ ${ }^{2}$ Dept. of Chem. and ${ }^{1,2}$ Centre on Functional Engineered \\ Nano Architectonics (FENA), University of California, \\ Los Angeles, California, 90095, USA
}

\begin{abstract}
Electro-conductive polyaniline (PANI) nanofiber based Surface Acoustic Wave (SAW) gas sensors have been investigated with hydrogen $\left(\mathrm{H}_{2}\right)$ gas. A template-free, rapidly mixed method was employed to synthesize polyaniline nanofibers using chemical oxidative polymerization of aniline. The nanofibers were deposited onto a layered $\mathrm{ZnO} / 64^{\circ} \mathrm{YX}$ $\mathrm{LiNbO}_{3} \mathrm{SAW}$ transducer for gas sensing applications. The novel sensor was exposed to various concentrations of $\mathrm{H}_{2}$ gas at room temperature. The sensor response, defined as the relative variation in operating frequency of oscillation due to the introduction of the gas, was $3.04 \mathrm{kHz}$ towards a $1 \% \mathrm{H}_{2}$ concentration. A relatively fast response time of $8 \mathrm{sec}$ and a recovery time of $60 \mathrm{sec}$ with good repeatability were observed at room temperature. Due to room temperature operation, the novel gas sensor is promising for environmental and industrial applications.
\end{abstract}

\section{INTRODUCTION}

Hydrogen is a colourless, odourless and flammable gas. Recognized as a possible alternative energy source, it burns cleanly and may be produced from renewable energy sources. Its small molecular size allows it to penetrate metals and affect their properties, such as strength and durability. Hydrogen has diverse applications in industry: petroleum transportation, cryogenic cooling, semi-conductor manufacturing processes, fuel cell technology, rocket engines and production of chemical substances [1]. Hydrogen sensing is important for the following applications: leakage detection, fire warning systems, biomedical applications and monitoring of environmental pollution.

Conducting polymers have received increasing interest as smart sensors due to their room temperature sensitivity, low production cost, ease of deposition onto a wide variety of substrates [2-3] and their rich chemistry for structural modifications [4-5].

Polyaniline is unique among the family of conducting polymers since its doping level can be controlled through a non-redox acid doping/base dedoping process [6]. By changing the doping level, the conductivity of polyaniline can be modified for specific applications. Polyaniline can exist in a range of oxidation states. The one that can be doped with an acid to a highly conductive state is called polyemeraldine (Figure 1: top). It consists of amine (-NH-) and imine $(=\mathrm{N}-)$ sites in equal proportions. The imine sites can be protonated to achieve an intermediate bipolaron form (Figure 1: middle) and finally by dissociation to a polaron lattice (Figure 1: bottom), resulting in high conductivity [7]. It is widely beleived that polarons are the charge carriers responsible for the high conductivity of doped polyaniline. By controlling the $\mathrm{pH}$ of the dopant acid solution any desired quantity of dopants can be added until all imine nitrogens are doped. Dopants can be removed by a reversible reaction with any common base.

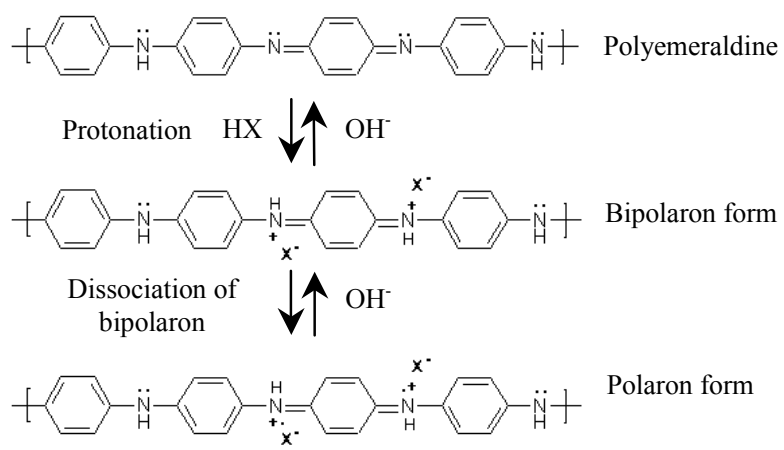

Figure 1. Polyaniline undoped form (top), intermediate bipolaron form (middle), and the fully doped acid form (bottom).

Since the conductivity of polyaniline depends on both the oxidation state of the main polymer chain and the degree of protonation of the imine sites [8], any interaction with PANI that alters either of these processes will affect its conductivity. Unlike acids and bases, redox active chemicals and gases can affect the conductivity of polyaniline by changing its inherent oxidation state. Depending on the extent of the redox reaction three different forms of polyaniline can be made: fully reduced leucoemeraldine, half oxidized emeraldine, and fully oxidized pernigraniline. The 
emeraldine form of polyaniline can be doped with a protonic acid to produce electrical conductivity [9]. Neutral, nonredox organic compounds, such as chloroform or toluene, are able to change the conductance of doped polyaniline films through swelling effects [10]. Adding functional guests into the polyaniline structural matrix, such as metals or enzymes could change polyaniline's electrical conductivity characteristics, leading to a broader scope for the design and development of polyaniline based sensors [11].

Nanostructured polyaniline, in the form of nanowires, nanotubes, nanofibers or nanorods can greatly improve carrier diffusion due to their high surface to volume ratio and large penetration depth for gas molecules [12-13]. Deposition of polyaniline on porous supports can also increase the surface area but extra care needs to be considered due to structural complexities [14-15].

Polyaniline nanofibers with a cylindrical morphology form a porous structure when deposited as a thin film. The nanofibers possess higher surface to volume ratios than ultrathin polyaniline films of the same thickness [16]. The threedimensional porous structure of a PANI nanofiber film allows for easy diffusion of gases into and out of the selective layer and the nano scale fiber diameters lead to rapid diffusion of gases into the polyaniline, resulting in fast sensor response and recovery times upon exposure to a number of gases [12-13].

Conventional polyaniline thin film sensors have a dependency on the deposited film thickness in their sensitivity [17]. Generally, sensor sensitivity increases with a reduction of film thickness as a thicker film has more inactive materials that does not react with gas species in a short period of time. However, thin film sensors are generally less robust than thick film sensors. On the other hand, sensitivity of a nanofiber polyaniline sensor is independent of layer thickness, due to the porous structure of the film. This advantage results in the capability of fabricating sensors with reproducible responses that have a large tolerance in thickness variation [12].

Although, nanostructured conducting polymers are very promising for sensors, there are not that many reports in the literature [12-13] [17-20]. To the best of our knowledge, polyaniline nanofibers have not yet been used as a sensitive layer in SAW devices for hydrogen gas sensing. However, polyaniline is being actively studied for hydrogen storage [21-23].

In our work, layered SAW devices were used as the transducing platform. Layered SAW transducers have attracted significant attention in recent years for sensing applications due to their higher sensitivity than their nonlayered counterparts. The deposition of a $\mathrm{ZnO}$ layer onto $64^{\circ}$ $\mathrm{YX} \mathrm{LiNbO}_{3}$ substrate forms a layered SAW structure with higher electromechanical coupling [24]. Shear-horizontal (SH) leaky SAW propagation is the dominant mode in this layered substrate.

For gas sensing, PANI nanofibers can be deposited onto the active area of a SAW device as a sensing layer. In a
SAW device, the change in electrical conductivity perturbs the velocity of the propagating acoustic wave due to piezoelectric effects. The deviations in velocity are monitored by measuring the changes in frequency of the sensing device. This change in frequency is directly proportional to the amount of a specific gas present in the environment, resulting in a quantitative determination of the presence of gas and its concentration [25].

In this paper, polyaniline nanofibers were synthesized from chemical oxidative polymerisation of aniline using a template-free, rapidly mixed method. Then a polyaniline nanofiber sensitive layer was formed on the layered SAW transducer for $\mathrm{H}_{2}$ gas sensing applications. Finally, the responses of the sensor to different $\mathrm{H}_{2}$ gas concentrations were determined.

\section{EXPERIMENTAL}

The sensor consisted of two-port resonators with 38 finger pairs in each input and output Inter Digital Transducers (IDT), 160 reflectors, $700 \mu \mathrm{m}$ aperture width and a periodicity of $40 \mu \mathrm{m}$. The centre-to-centre distance between the IDTs was 48 wavelengths. The IDTs were formed by patterning an $80 \mathrm{~nm}$ layer of gold and a $20 \mathrm{~nm}$ titanium layer. The titanium layer is added to improve adhesion of the gold thin film.

A $\mathrm{ZnO}$ layer of $1.2 \mu \mathrm{m}$ in thickness was deposited on the surface of the $64^{\circ} \mathrm{YX} \mathrm{LiNbO}_{3}$ substrate to form the layered structure. A radio frequency (RF) magnetron sputterer was used to deposit from a $99.99 \%$ pure $\mathrm{ZnO}$ target with rf power of $120 \mathrm{~W}$. The sputtering gas was $40 \% \mathrm{O}_{2}$ in Ar with $10^{-2}$ torr pressure and $260^{\circ} \mathrm{C}$ substrate temperature for 60 minute periods.

The previous methods for making polyaniline nanostructures usually require structure-directing templates, such as zeolite channels [26] or nanoporous membranes [27], surfactants [28], etc. These complex synthetic conditions require removal of the templates at the end of the reaction, resulting in low production rates. Recently, we have introduced template-free, rapidly mixed method to synthesize polyaniline nanofibers using chemical oxidative polymerisation of aniline [29-30]. The polymerisation is performed in an aqueous solution where aniline is rapidly polymerised in $1 \mathrm{M}$ acid by the quick addition of the oxidant. Due to the immediate interaction between the monomer and the oxidant, the primary reaction product, nanofibers, is the main morphology present. After completion of the reaction, the product is collected for purification. Washing or dialyzing with water gives pure doped polyaniline that can be dedoped by washing or dialyzing with ammonia. The average diameter of the polyaniline nanofibers is about 50 $\mathrm{nm}$ with lengths up to several microns.

Doped polyaniline nanofiber dispersions were drop cast onto the active area of the transducers using a micro pipette. They were then left to dry in a clean, dry place for one day. Hydrogen gas sensors are made up of two important physical components: the sensitive polyaniline nanofiber layer, which 
interacts with the gas media and the SAW transducer, which converts the chemical signal to an electrical signal. A frequency counter was used to measure the resonant frequency of the transducer upon exposure to the $\mathrm{H}_{2}$ gas. The operational frequency of the sensor was found to be approximately $108.2 \mathrm{MHz}$ in synthetic air at room temperature. A scanning electron microscopy (SEM) image (Fig. 2) reveals that the polyaniline nanofiber layer deposited on the substrate consists of a large quantity of wire-like nanostructures.

The sensor device was mounted inside an enclosed environmental cell (Fig. 3). The four mass flow controllers (MFC) were connected to form a single output that supplied gas to the cell (Fig. 4). Teflon tubing ensured the minimization of atmospheric changes. A constant flow rate of 0.2 litres per minute was delivered via the MFCs.

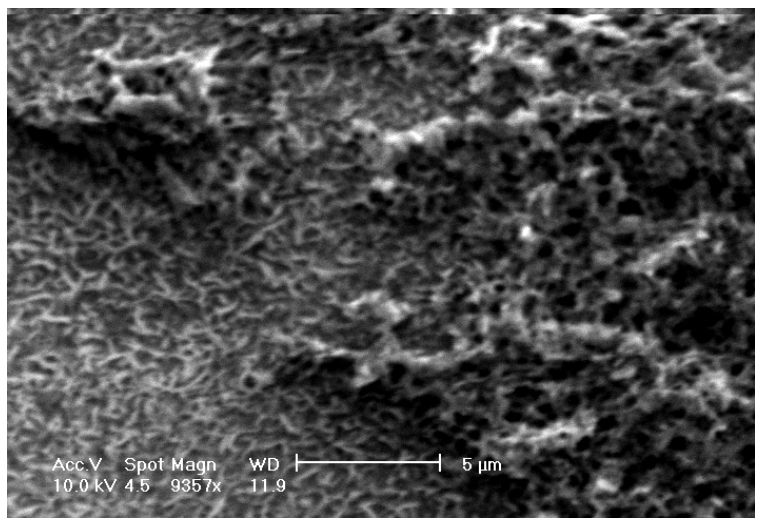

Figure 2. SEM image of polyaniline nanofibers on the SAW device.

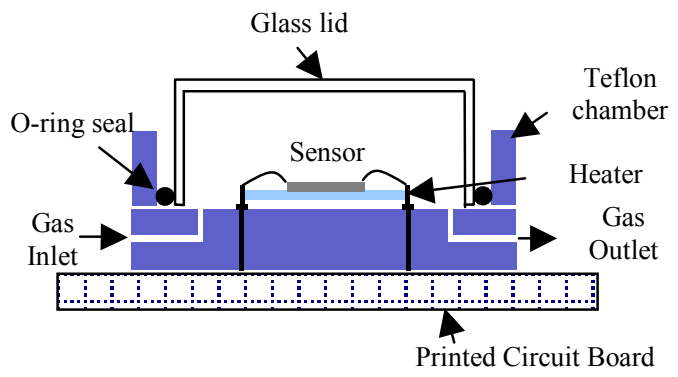

Figure 3. The experimental set-up for sensor testing.

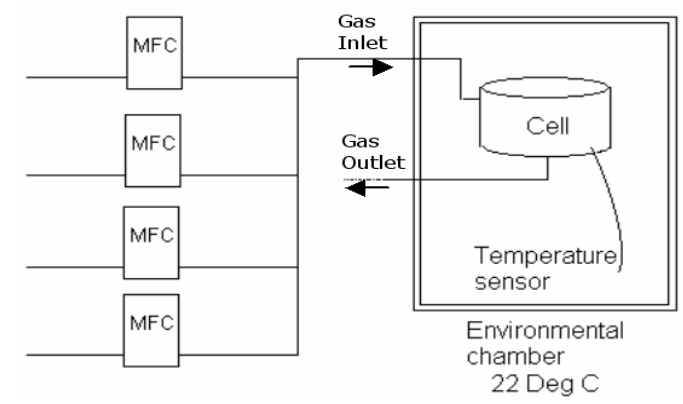

Figure 4. Gas calibration system used for testing PANI nanofiber based sensors.
A computerized gas calibration system was used to vary the concentration of $\mathrm{H}_{2}$ gas in the synthetic air. Gas exposure time was fixed at one minute for each pulse of $\mathrm{H}_{2}$ gas and the cell was purged with synthetic air for two minutes between each pulse to allow the surface of the sensor to regain atmospheric conditions. Using the layered SAW device as a positive feedback element in a closed loop circuit with an amplifier, an oscillator was formed. The sensor was exposed to hydrogen gas pulse sequence of $0.06 \%, 0.125 \%, 0.25 \%$, $0.50 \%, 1 \%$, and $0.06 \%$ concentrations in synthetic air at room temperature. A Fluke high-resolution counter (PM66860B) was used to measure the oscillation frequency. The sensor responses were displayed in real-time and saved for off-line processing and analysis.

\section{RESULTS}

The dynamic response of the sensor to different $\mathrm{H}_{2}$ concentrations is shown in Fig. 5. The introduction of $\mathrm{H}_{2}$ gas to the sensor surface causes reduction of the device's resonant frequency due to an increase in the polyaniline nanofiber layer's conductivity. The sensor response, defined as the relative variation in operating frequency of oscillation due to the interaction with the target gas, is $3 \mathrm{kHz}$ towards $1 \%$ of $\mathrm{H}_{2}$ at room temperature.

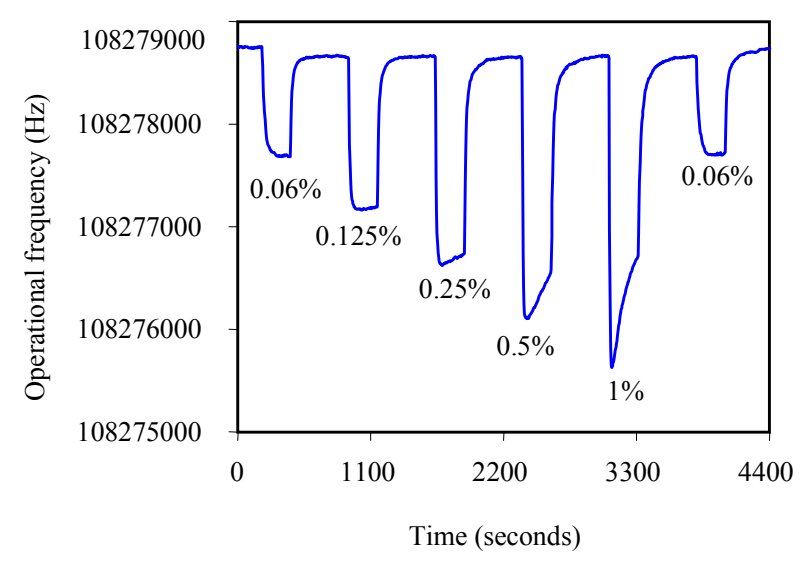

Figure 5. Dynamic response of a PANI nanofiber based $\mathrm{ZnO} / 64^{\circ} \mathrm{YX}$ $\mathrm{LiNbO}_{3} \mathrm{SAW}$ sensor towards $\mathrm{H}_{2}$ at room temperature .

A relatively fast response time of 8 seconds and a recovery time of 60 seconds were observed. Reproducibility was observed as indicated when a second pulse of $0.06 \% \mathrm{H}_{2}$ was introduced into the sensor chamber. It was found that the polyaniline nanofiber based sensor gives repeatable responses of the same magnitude with good baseline stability. The response magnitude variation of the sensor to different $\mathrm{H}_{2}$ concentrations is shown in Fig. 6. The frequency shift increases non-linearly with the increase of $\mathrm{H}_{2}$ concentrations. At lower concentrations of $\mathrm{H}_{2}$, the frequency shift increases linearly with an increase in $\mathrm{H}_{2}$ concentration. However, at higher concentrations of $\mathrm{H}_{2}$, the sensor response tends to saturate. 


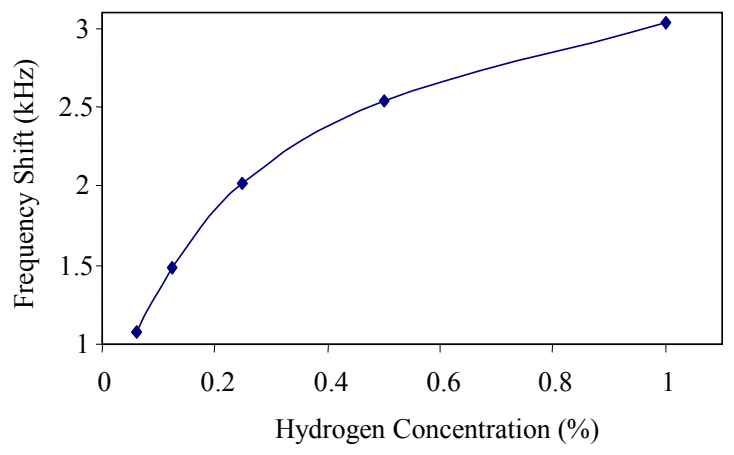

Figure 6 Frequency shift $(\mathrm{kHz})$ versus $\mathrm{H}_{2}$ gas concentrations (\%) at room temperature.

\section{CONCLUSIONS}

We have fabricated SAW gas sensors based on the polyaniline nanofibers synthesized by a template-free rapidly mixed polymerisation of aniline. Novel SAW gas sensors based on these nanofibers were investigated towards different concentrations of $\mathrm{H}_{2}$ gas at room temperature. The sensor response, defined as the relative variation in resonant frequency, is $3 \mathrm{kHz}$ towards $1 \%$ of $\mathrm{H}_{2}$ at room temperature. A relatively fast response and recovery time with good repeatability and base-line stability were observed. Such interesting sensing characteristics at room temperature operation, pave the way to fabricate low power sensors using low cost polyaniline based nanofibers.

\section{ACKNOWLEGMENT}

The UCLA group would like to thank the Microelectronics Advanced Research Corp. for financial support.

\section{REFERENCES}

[1] X. Bevenot, A. Trouillet, C. Veillas, H. Gagnaire and M. Clement, "Hydrogen leak detection using an optical fibre sensor for aerospace applications," Sensors and Actuators B, vol. 67, pp. 57-67, 2000.

[2] M. Thust, M. Schoning, P. Kordos, and H. Luth, "Porous silicon as a substrate material for potentiometric biosensors," Measure. Sci. Technol., vol. 7, pp. 26-29, 1996.

[3] K. Li, D.C. Diaz, Y. He, J.C. Campbell, and C. Tsai, "Electroluminescence from porous silicon with conducting polymer film contacts," Appl. Phys. Lett., vol. 64, pp. 2394-2396, 1994.

[4] T. Kikas, H. Ishida, and J. Janata, "Chemical plume tracking. 3. ascorbic acid: a biologically relevant marker," Anal. Chem., vol. 74, pp. 3605, 2002.

[5] J. Janata, and M. Josowicz, "Conducting polymers in electronic chemical sensors," Nat. Materials, vol. 2, pp. 19-24, 2003.

[6] W. S. Huang, B. D. Humphrey, and A. G. MacDiarmid, "Polyaniline, a novel conducting polymer: Morphology and chemistry of its oxidation and reduction in aqueous electrolytes," J. Chem. Soc. Faraday Trans., vol. 82, pp. 2385, 1986.

[7] G. Wallace, and P. Teasdale, "Conductive electro-active polymers," Technomic Pub. Co. Inc., USA, pp. 107, 1997.

[8] A.G. MacDiarmid, "Synthetic metals: A novel role for organic polymers," Synth. Met., vol. 125, pp. 11-22, 2001.
[9] S. Kaplan, E. M. Conwell, A. F. Richter and A. G. MacDiarmid, "Solid-state C-13 NMR characterization of polyanilines," J. Am. Chem. Soc., vol. 110, pp. 7647-7651, 1988.

[10] J.G. Roh, H.R. Hwang, J.B. Yu, J.O. Lim, and J.S. Huh, "Oxidant effects on polypyrrole and polyaniline sensor for several volatile organic gases," J. Macromol. Sci, Pure Appl. Chem., vol. A39, pp. 1095-1105, 2002.

[11] J.N. Barisci, C. Conn, and G.G. Wallace, "Conducting polymer sensors," Trends Polym. Sci., vol. 4, pp. 307, 1996.

[12] J. Huang, S. Viriji, B.H. Weiller, and R.B. Kaner, "Nanostructured polyaniline sensors," Chem. Eur. J., vol. 10, pp. 1314-1319, 2004.

[13] S. Virji, J. Huang, R.B. Kaner, and B.H. Weiller, "Polyaniline nanofiber gas sensors: Examination of response mechanisms," Nanoletters, vol. 4, pp. 491-496, 2004.

[14] G.E. Collins, and L.J. Buckley, "Conductive polymer-coated fabrics for chemical sensing," Synth. Met., vol. 78, pp. 93-98, 1996.

[15] Y. Wang, and R. Weiss, "Conductive polymer foams as sensors for volatile amines," Chem. Mat, vol. 15, pp. 375-377, 2003.

[16] U. Kang, and K.D. Wise, "A high-speed capacitive humidity sensor with on-chip thermal reset", IEEE Trans. Electron Devices, vol. 47, pp. 702-710, 2000.

[17] S. J. Huang, S. Virji, B.H. Weiller, and R.B. Kaner, "Polyaniline nanofibers: facile synthesis and chemical sensors," J. Am. Chem. Soc., vol. 125, pp. 314-315, 2003.

[18] S. Virji, J. D. Fowler, C. O. Baker, J. Huang, , R.B. Kaner, and B.H Weiller, "Polyaniline nanofiber composites with metal salts: chemical sensors for hydrogen sulfide," Small, vol. 1, no. 6, pp. 624-627, 2005.

[19] G. Li, C. Martinez, J. Janata, J. A. Smith, M. Josowicz, and S Semancik, "Effect of morphology on the response of polyanilinebased conductometric gas sensors: nanofibers vs. thin films," Electrochem. and Solid-State Lett., vol. 7, issue 10, pp. H44-H47, 2004.

[20] D. J. Yao, and Y. R. Yang, "Bio-chemical sensor using polyaniline nanofibers for sensing amino-group type of gas," Proc. of IEEE Int. Conf. on Inform. Acqui., Hong Kong and China, June 2005.

[21] S. J. Cho, K. S. Song, J. W. Kim, and K. Choo, "Hydrogen sorption in $\mathrm{HCl}$-treated polyaniline and polyoyrrole: new potential hydrogen storage media," Fuel Chem. Div., 224 $4^{\text {th }}$ Nat. M. of the Am. Chem. Soc., vol. 47, pp. 790-791, 2002.

[22] W. R. Schmidt, " Hydrogen storage in polymer-dispersed metal hydrides (PDMH)," Proc. of the 2001 DOE Hydrogen Prog. Review, 2001.

[23] B. Panella, L. Kossykh, U. D. Weglikowska, M. Hirscher, G. Zerbi, and S. Roth, "Volumetric measurement of hydrogen storage in HCltreated polyaniline and polypyrrole," Synth. Met., vol. 151, pp. 208210, 2005.

[24] K. Nakamura, T. Shoji, and H. B. Kang, "Growth of ZnO films on (012) $\mathrm{LiTaO}_{3}$ by ECR-MBE and determination of their polarity," Proc. Int. Symp. App. Ferroelec., pp. 467-470, 2000.

[25] S. J. Ippolito, K. K. Zadeh, A. Trinchi, W. Wlodarski, and M. Tobar, "Layered SAW nitrogen dioxide sensor based on a $\mathrm{ZnO} / 36^{\circ} \mathrm{YX}$ $\mathrm{LiTaO}_{3}$ structure with WO3 selective layer," Proc. of IEEE Int. Freq. Cont. Symp. And PDA Exh., pp. 931-934, 2003.

[26] C.G. Wu, and T. Bein, "Conducting Polyaniline Filaments in a Mesoporous Channel Host," Science, vol. 264, pp. 1757-1759, 1994.

[27] C.R. Martin, "Template Synthesis of Electronically Conductive Polymer Nanostructures," Acc. Chem. Res., vol. 28, pp. 61-68, 1995.

[28] L. Yu, J. I. Lee, K.W. Shin, C.E. Park, and R. Holze, "Preparation of aqueous polyaniline dispersions by micellar-aided polymerization," J. Appl. Polym. Sci., vol. 88, pp. 1550-1555, 2003.

[29] J. Huang, and R.B. Kaner, "A general chemical route to polyaniline nanofibers," J. Am. Chem. Soc., vol. 126, pp. 851-855, 2004.

[30] J. Huang and R. B. Kaner, "Nanofiber formation in the chemical polymerization of aniline: A mechanistic study," Angew. Chem. Int. Ed., vol. 43, pp. 5817-5821, 2004. 